\title{
Sarduy-Derrida: cenizas de la escritura o la escritura como ceniza. Una lectura sobre la memoria y el olvido
}

\section{Sarduy-Derrida: Writing's Ashes or Writing as Ashes. A Reading on Memory and Oblivion}

\author{
Lorena FIORETTI KATZ \\ Universidad Nacional de Córdoba-CONICET (Argentina) \\ lorenfio@unsl.edu.ar
}

Recibido: 10/11/2010

Aceptado: 20/06/2011

\section{Resumen}

El presente artículo pretende recorrer el camino a través del cual la escritura, la différance y las cenizas, cuestionan el concepto de tiempo lineal por el que hemos construido la historia e interpretado su devenir. Sostenemos que estos conceptos nos permiten pensar un modo diverso de abordar la temática de la memoria y el olvido. Pretendemos acercarnos a la misma, a través de la escritura de Jacques Derrida y Severo Sarduy, porque entendemos que estas líneas textuales aspiran a una construcción ética y estética que supone puntos de fuga o resistencias contra la intención totalizadora del discurso ontológico. Si bien la propuesta que procuramos realizar se inscribe en dos órdenes heterogéneos, el de la literatura y la filosofía, ambos se articulan en el borde que implica el espacio textual.

Palabras clave: ceniza, escritura, différance, tiempo, memoria, olvido.

\begin{abstract}
In this article we undertook the path where the writing, the differrance and the ashes call the lineal time concept -by which the history has been constructed and the becoming interpreted- into question. We believe that such concepts allow us to
\end{abstract}


diversely think the topic of memory and forgetfulness. Likewise, we approach the topic through the writing of Jacques Derrida and Severo Sarduy because we think that those textual lines tend to an ethical and esthetical construction which implies vanishing points or resistances towards the totalizing aim of ontological discourse. Although the proposal we are addressing here is inscribed into two heterogeneous orders, namely literature and philosophy, both are articulated in the border defined by the textual space.

Keywords: Ash, script, différance, time, memory, forgetfulness.

\section{Sumario}

1. El origen de la reflexión

2. Del libro a la escritura

3. I- Primera aproximación: La différance y la escritura

4. II- Segunda aproximación: La Pizarra Mágica o la escena de la escritura psíquica

5. Del texto neobarroco: Severo Sarduy

6. La experiencia de la escritura: Sarduy y Derrida

\section{El origen de la reflexión}

De un lado y otro del signo, esas búsquedas, cuya verdadera ambición estas notas no han llegado a definir, demuestran que, a pesar de sus resistencias, el hombre se adentra en el plano de la literalidad que hasta ahora se habia vedado, formulando esa pregunta sobre su propio ser, sobre su humanidad que es ante todo la del ser de su escritura. Severo Sarduyl

Y en el comienzo hay cenizas.

Pero los días son una red de triviales miserias, ¿y habrá suerte mejor que la ceniza de que está hecho el olvido?; se pregunta Borges. Tal vez seamos eso: cenizas. Cenizas que vienen del fuego, fuego del cual la vida deviene, pero que en el mismo movimiento, la vida devora. Y al final sólo quedan cenizas. Pero en el principio, también.

1 Sarduy, S., Obra Completa, coord. Gustavo Guerrero y François Wahl, Barcelona, Galaxia Gutemberg, 1999, p.1137. 
Intentaremos pensar, junto a Derrida y a Sarduy, la metáfora ${ }^{2}$ de las cenizas en relación a la temática de la memoria y el olvido, ya que la misma nos permite articular los motivos de la escritura y el tiempo. No pretendemos trazar una línea de continuidad imaginaria entre Derrida y Sarduy, como tampoco interpretar la letra de Sarduy a partir de una especie de coordenadas derridianas, porque al decir de Lacan, los poetas siempre llevan la delantera. Tal vez se trate, como expresa Derrida en ocasión de un homenaje a Riddle, de someter a la prueba de la literatura el pensamiento filosófico. En cualquier caso, intentaremos interpretar, leer, convertir en preguntas, aquello que se cuela entre la escritura de Derrida y la de Sarduy. Aquello que en sus textos señala una poética de lo otro. Una lógica pervertida del sentido.

Reflexionar en torno a la memoria y el olvido remite siempre a un lugar. Lugar de una inscripción, pero también de un acontecimiento. Remite a un espacio temporal pasado, pero también nos dirá Derrida, a uno por-venir. Espacio laberíntico del que intentaremos dar cuenta en este esbozo de cartografía quebrada donde el comienzo y el final no hacen más que dispersarse multiplicándose. $\mathrm{O}$, lo que es lo mismo, no hay un comienzo y un final, al menos, como lo entendíamos hasta ahora.

Escribir sobre la memoria y el olvido supone una referencia ineludible al sujeto. Si el proceso subjetivo es siempre heredero de un duelo, de múltiples duelos; de lo que se trata es de aprehender el movimiento infinito e inacabado en el que ahora los muertos (por los) que lloramos, estuvieron desde siempre en nosotros. Proceso testamentario en el que se juega la herencia. Cartografía particular por la que se perturban los espacios temporales en los que devenimos (en el) mundo.

El duelo consiste en reconocer que los muertos están ahora sólo "en nosotros", las imágenes sólo existen "para nosotros". Y sin embargo hay un límite a esta interiorización; proviene no ya de alguna impermeabilidad de la frontera entre dos espacios homogéneos, sino de una organización diferente del espacio-tiempo. Porque la parte que está "en nosotros" viene antes que el todo, es mayor que él; viene antes que nosotros. La parte que nosotros vemos, nos ve y nos mira primeros, como nuestro origen y nuestra ley. ${ }^{3}$

La memoria se forma luego de un proceso de duelo, pero la interiorización absoluta del otro no se logra jamás. Lo que se produce es una reorganización del espacio. Se trata entonces, del proceso de duelo inacabado-imposible, de los restos que quedan, que restan, que permanecen en la forma de la huella que funda al sujeto. Es la posibilidad de este imposible lo que gobierna toda lógica o más bien retórica del duelo y describe de esta manera la esencia de la memoria.

\footnotetext{
2 ¿Es posible hablar hoy más allá de las metáforas? Siguiendo a Bergson, como no existe un lenguaje no-metafórico, tal vez de lo que se trate sea de multiplicar las metáforas antagónicas. En ese camino nos hallamos.

3 Brault y Nass, «Contar con los muertos. Jacques Derrida y la política del duelo», en Derrida, J., Cada vez única, el fin del mundo, Valencia, Pre-textos, 2005, p.31.
} 
Acaso abordar algunos de estos textos nos permita conocer el modo en el que una determinada herencia es aprehendida, sabiendo que el devenir del sujeto de la escritura, se da en un complejo "sistema de relaciones entre las capas: del bloque mágico, de lo psíquico, de la sociedad, del mundo. En el interior de esta escena, la simplicidad puntual del sujeto clásico desaparece."4

Pretendemos acercarnos a esta temática a través de la escritura de Jacques Derrida y Severo Sarduy porque entendemos que estas líneas textuales aspiran a una construcción ética y estética que supone puntos de fuga o resistencia contra la intención totalizadora del discurso ontológico. Este cruce no es desde ya una autorización recíproca de coincidencias explícitas, sino el encuentro en un punto seminal que diverge para poder seguir transitando devenires múltiples y azarosos. Si bien el recorrido que procuramos realizar se inscribe en dos órdenes heterogéneos, el de la literatura y la filosofía, ambos se articulan en el borde que implica el espacio textual.

Partimos del supuesto, siguiendo a Asensi, de que las relaciones entre filosofía y crítica literaria sólo pueden plantearse en términos de conflicto, paradoja y límite. ¿De qué modo es posible una lectura a dos voces de una misma problemática? Se tratará de una contaminación entre los textos de Derrida y de Sarduy, cosa que por otra parte, ellos mismos realizan insistentemente, diseminando y perturbando discursos-espacios heterogéneos. Pretendemos establecer un diá-logo, lo que supone, en primer lugar, realizar una selección de algunos fragmentos a partir de los que intentaremos tejer esta propuesta. Y es esta lógica del corte, del collage, el modo, la forma, es decir, desde ya, el contenido mismo de lo que intentaremos plantear. Esta lógica del retazo está íntimamente ligada a la teoría del injerto derridiano, con la que se quiere señalar que toda escritura siempre es un modo de tejer diversas lecturas-escrituras anteriores.

Derrida dialoga con el discurso freudiano en torno a la pregunta por la memoria y el olvido en el horizonte de la interpelación a la subjetividad. El psicoanálisis es uno de los discursos que ha trabajado particularmente la relación sujeto-memoria-olvido en el marco de una psicopatología de la vida cotidiana, es decir, no ya como una falta o error, sino el lugar mismo donde algo de la verdad del sujeto sería convocada. Por otro lado, la relación recuerdo-olvido no puede ser pensada desde una lógica binomial de opuestos irreconciliables sino como momentos de un proceso simultáneo en el que el olvido designa aquello que es imposible olvidar5.

\footnotetext{
${ }_{4}^{4}$ Derrida, J., Posiciones, Valencia, Pre-textos, 1977, p. 118.

5 En una perspectiva similar, la mirada nietzscheana acerca de la verdad surgiría a partir de una genealogía del error, la voluntad de verdad, de la voluntad de engañar. Ambos presupuestos no son sólo una inversión, sino la perversión misma del concepto de verdad-mentira. "Una génesis (Entstehung) como ésa de lo contrario vendría a contradecir su origen mismo. Sería una antigénesis. Haría la guerra a su propia filiación, piensa «el metafísico de todos los tiempos», sería como un nacimiento monstruoso, una procedencia «imposible» (Solcherlei Entstehung ist unmöglich)" en Derrida, J, Politicas de la amistad, seguido de El oído de Heidegger, Ed. Trotta, Madrid, 1998, p. 52.
} 
Los diversos motivos que exponemos como las coordenadas de nuestra propuesta, suponen la pregunta y la interpelación a la concepción mundana del tiempo lineal y cronológico. La memoria implica un esfuerzo de conservación que supera el paso del tiempo. Pero ¿de qué tiempo? ¿Cómo entender el tiempo que se $v a$ entre huella y huella, entre aquello que se quema y sus cenizas como espaciamiento en el que se articula el espacio y el tiempo? ¿Qué hay entre la inscripción del acontecimiento y el acontecimiento mismo? Se tratará de recorrer el camino a través del cual la escritura, la différance y las cenizas, cuestionan el concepto de tiempo lineal por el que hemos construido la historia e interpretado su devenir.

\section{Del libro a la escritura}

Derrida abre De la gramatología diciendo que la concepción de la escritura como pintura ya no puede sostenerse sino para denunciar la represión ideológica que deviene gradualmente objeto de especulación y fetiche de la cultura occidental y que culmina en el modo de producción capitalista. La escritura no es sólo un instrumento al servicio del acontecer humano sino que, de alguna manera, es a partir de su estructuración que este acontecer tiene lugar. El lenguaje es producto y produce las relaciones sociales, movimiento complejo que supera las clásicas relaciones causa-efecto y anterior-posterior, entre otras. En general, la escritura ha sido comprendida como el gesto inocente y reproductivo, o como el pecado en sentido moral. Posiblemente, la escritura encierra la complejidad indecidible en la que nos hallamos presos.

El desarrollo teórico que Derrida realiza hacia finales de la década de los 60' está centrado en la pregunta por aquello que el pensamiento occidental ha olvidado y por este olvido mismo. Junto a Heidegger, Nietzsche, Freud, Saussure; pero también más allá de ellos, comenzará un camino que transitará hasta su muerte en relación a la pregunta por la différance, por un pensamiento de la diferencia y sus consecuencias éticas y políticas.

Lo que es insoportable y fascinante es esta intimidad que mezclaría la imagen con la cosa; la grafía con la fonía, hasta un punto tal que por un efecto de espejo, de inversión y de perversión, el habla aparece otra vez como el speculum de la escritura que "usurpa así el papel principal". La representación se une con lo que representa hasta el punto de hablar como se escribe, se piensa como si lo representado sólo fuera la sombra o el reflejo del representante. Promiscuidad peligrosa, nefasta complicidad entre el reflejo y lo reflejado que se deja narcisísticamente seducir. En este juego de la representación el punto de origen se vuelve inasible. Hay cosas, las aguas y las imágenes, un remitirse infinito de unas a otras, pero ninguna fuente. No hay ya origen simple. ${ }^{6}$

6 Derrida, J., De la Gramatología, Siglo XXI, España, 2002[1969], p. 69. 
Nos aproximaremos a los escritos de Derrida a partir de algunos motivos que actuarán como claves de lectura en la comprensión de la problemática que este trabajo quiere convocar.

\section{I- Primera aproximación: La différance y la escritura}

Junto a otros motivos, Derrida intenta con la différance ${ }^{7}$ la crítica a la metafísica occidental, y con ella, a los discursos constituidos bajo su abrigo. Este neologismo surge al interior de la pregunta por la escritura. Una aproximación semántica al neologismo nos lleva al verbo diferir (del latino differre) que describe la acción de dejar para más tarde, de tomar en cuenta el tiempo y las fuerzas en una operación que implica un movimiento económico, un rodeo, una demora, un retraso, una reserva. La différance supone la temporización y el espaciamiento. En este sentido, differre no es la traducción directa y simple de la palabra griega diapherein. La otra acepción de diferir es no ser idéntico, ser otro, discernible, diferenciarse, ser diferente. La palabra différance supone un matiz más: la $a$ que inaugura el neologismo viene del participio presente "difiriendo", lo que señala una acción en curso, antes que haya concluido con un efecto de diferencia como diferente. Este tono, es decir, la terminación "ance" también sugiere en francés una acción que permanece indecisa entre lo activo y lo pasivo. Es una acción que no responde ni a un agente (voz activa) ni a un paciente (voz pasiva), sería una voz media que implica una cierta transitividad.

Ahora bien, ¿cómo se conjugan estos matices en la problemática de la escritura que Derrida está pensando? Lo hacen en el signo, ya que éste nombra aquello que no está presente, que está diferido en su aparecer. El signo representa lo presente en su ausencia. El signo es esa presencia diferida, anunciada y recordada. "Siguiendo una semiología clásica, la sustitución del signo por la cosa misma es a la vez segunda y provisional: segunda desde una presencia original y perdida de la que el signo vendría a derivar; provisional con respecto a esta presencia final y ausente en vista de la cual el signo sería un movimiento de mediación." 8 La escritura es uno de los modos de esta duplicación que de alguna manera está más cerca de la muerte, que hace presente la muerte del (de quien) habla, el hecho de que escribimos porque ya no hay habla.

Estas tesis acerca de la escritura para imponerse han tenido que disimular su historia en el acto de su re-producción. El concepto de escritura estuvo siempre domi-

\footnotetext{
7 En el presente trabajo mantendremos la palabra en francés porque consideramos que permite el juego que nos propone Derrida, es decir, la imposibilidad de oír su diferencia ortográfica. La traducción castellana como diferancia, consideramos que oblitera este juego.

8 Derrida, J., Márgenes de la filosofía, Editorial Cátedra, Madrid, 2006[1989], p.45.
} 
nado por una mirada etnocéntrica, anudada íntimamente a la historia de la metafísica que, desde los presocráticos a Heidegger, ha destinado a la escritura a un lugar secundario en relación al habla plena que es la conexión directa, el aparecer del logos que se halla en el origen de la verdad. La verdad, el logos y el habla son los conceptos que han circunscripto en resumidas cuentas y asumiendo todas la variables y matices más o menos radicales, la historia del pensamiento occidental. El esfuerzo de Derrida está orientado a una ciencia de la escritura que pueda y deba para devenir tal, liberarse (movimiento complejo que admite desde ya todas las contradicciones) de la metáfora, la metafísica y la teología. Para ello hay que comenzar por poner en tela de juicio el concepto mismo de escritura. Pero la revisión del carácter secundario de la escritura no supone valorar ahora una escritura original, una différance primordial. Con el motivo de la différance se quiere poner en tela de juicio el valor de arkhé y telos, ya que ambos denotan presencia. Junto al signo, lo que se intenta subvertir es la autoridad de la presencia y de la ausencia como su simple contrario. "La différance es el "origen" no-pleno, no-simple, el origen estructurado y diferente (de diferir) de las diferencias. El nombre de "origen", pues, ya no le conviene."9

Todas las diferencias son pues efectos de la différance: "No han caído del cielo ya listas; no están más inscritas en un topos noetos que prescritas en la cera del cerebro. Si la palabra "historia" no comporta en sí misma el motivo de una represión final de la diferencia, se podría decir que únicamente las diferencias pueden ser de entrada y totalmente 'históricas'."10 Si para Saussure, la lengua es necesaria para que el habla sea inteligible, produzca todos sus efectos y se establezca; podríamos decir junto al lingüista que 'históricamente', el acto del habla precede a la lengua. En este sentido, la différance sería el movimiento según el cual todo código, es decir, todo sistema de repeticiones se constituye históricamente como un entramado de diferencias. Ahora bien, Derrida no desconoce las resonancias metafísicas que poseen muchos de estos términos. Pero ¿cómo hablar en otra lengua? ¿Cómo hablar de otra manera si el lenguaje, tal como aparece en el mundo occidental, es lo que permite el pensamiento? Se trata de tender a un pensamiento más allá de de la 'lengua metafísica', recorrido que supone el paso por esta y su tachadura.

En este punto podemos decir que la différance es tan estática como genética y tan estructural como histórica. Además, la différance es pasible de algunas sustituciones no sinónimas que dependerán del contexto, tales como: 'espaciamiento', 'archi-escritura', 'suplemento', 'himen', etc.

\footnotetext{
${ }^{9}$ Ibidem, p. 47.

10 Ibidem, p. 47.
} 


\section{La différance y el tiempo}

El tema de la temporalización11 es un motivo central en la pregunta por la memoria, por el deseo del recordar, de guardar en el tiempo, pero también de conservar por un movimiento de destrucción esencial aquello que corroe el tiempo y el propio deseo de recordar. La huella trastoca la comprensión del tiempo como la suma de presentes sucesivos. El presente comprendido a partir de la différance ya no puede ser entendido como el aparecer de sí para sí mismo, sino que siempre está relacionado con lo que no es él, con las múltiples marcas pasadas que hay en él, pero además, unido irrenunciablemente al futuro. El espaciamiento nos permite, de esta manera, comprender el espacio y el tiempo como síntesis no originarias, o en todo caso, el origen es disyunto y está quebrado desde siempre. Pero "no se trata de complicar la estructura del tiempo conservando en él su homogeneidad y su sucesividad fundamentales, mostrando, por ejemplo, que el presente pasado y el presente futuro constituyen originariamente, dividiéndola, la forma del presente viviente."12 El fragmento que a continuación transcribimos sintetiza de manera privileguada el cuestionamiento del tiempo lineal, a partir de la différance:

La différance es lo que hace que el movimiento de significación no sea posible más que si cada elemento llamado "presente", que aparece en la escena de la presencia, se relaciona con otra cosa, guardando en sí la marca del elemento pasado y dejándose ya hundir por la marca de su relación con el elemento futuro, no relacionándose la marca menos con lo que se llama el futuro que con lo que se llama el pasado, y constituyendo lo que se llama el presente por esta misma relación con lo que no es él: no es absolutamente, es decir, ni siquiera un pasado o un futuro como presentes modificados. Es preciso que le separe un intervalo de lo que no es él para que sea él mismo. [...] Y es esta constitución del presente, como síntesis "originaria" e irreductiblemente no simple, pues, sensu estricto, no-originaria, de marcas, de rastros de retenciones y de protecciones (para reproducir aquí, analógicamente y de manera provisional, un lenguaje fenomenológico y trascendental que se revelará enseguida inadecuado) que yo propongo llamar archi-escritura, archi-rastro o diferancia. Esta (es) (a la vez) espaciamiento (y) temporización. ${ }^{13}$

Retomemos el hilo de la trama. Las diferencias son efectos de la différance que está en marcha ya desde siempre en el no-origen: no es derivada. Saussure también lo ha señalado de alguna manera al decir que la lengua no es una función, un pro-

11 El tiempo es uno de los modos en los que se articula la différance y la huella. Sería para Freud, según Derrida, el tema del efecto de retardo (nachträglich). Es interesante hacer notar que en el universo textual psicoanalítico la palabra alemana nachträglichkeit es traducida al francés por la expresión après coup y que al inglés la Standart Edition vierte como "deferred action".

12 Derrida 2002[1969], op.cit. (nota 6), p. 107.

13 Derrida 2006[1989], op.cit. (nota 8), pp. 48-49. 
ducto del sujeto hablante. Es de alguna forma al revés, es el sujeto quien está inscrito en la lengua. La lengua inscribe el cuerpo del sujeto: "no se hace sujeto hablante más que conformando su habla, incluso en la llamada "creación», incluso en la llamada «transgresión», al sistema de prescripciones de la lengua como sistema de diferencias, o al menos a la ley general de la diferencia..."14 La différance es esta relación entre la lengua y el habla, y el rodeo que el sujeto debe "realizar" para hablar, pero no ya como una actitud activa y consciente, es decir, voluntaria.

\section{II- Segunda aproximación: La Pizarra Mágica o la escena de la escritura psíquica}

Podríamos decir, junto a Derrida, que el motivo fundamental del pensamiento de Freud es el funcionamiento de la economía de fuerzas que cuestiona la primacía de la presencia como conciencia. Las dos posibilidades que nos permite la différance se anudan en la teoría freudiana, es decir, la différance como espaciamiento y como temporización. "No se puede describir el origen de la memoria y del psiquismo como memoria en general (consciente o inconsciente) más que tomando en consideración la diferencia entre los razonamientos. Freud lo dice expresamente. No hay roce $\sin$ diferencia y diferencia sin marca." 15 Desde esta perspectiva, Derrida lee algunos de los textos paradigmáticos de Freud. En 1967, publica La escritura y la diferencia, libro que reúne una pluralidad de artículos orientados fundamentalmente a leer a algunos de sus contemporáneos, buscando en los textos las marcas que ha dejado el camino de la diferencia como escritura. Freud y la escena de la escritura, es el texto dedicado a su lectura de Freud.

En la obra de Freud la relación de la memoria con la concepción topológica de la huella mnémica16 es fundamental, ya que la memoria es considerada la base a partir de la que lo psíquico deviene. Luego de una larga búsqueda de metáforas que

\footnotetext{
14 Ibidem, p. 50.

15 Ibidem, pp. 53-54.

16 La palabra huella hace referencia a una "señal que deja en un lugar el pie de una persona o un animal o la rueda de un carro. Señal o vestigio que queda de una cosa. Impresión que deja en alguien una persona, un acontecimiento.”(Larousse, 2005:536) En el contexto específicamente psicoanalítico, Freud utiliza el término "huella mnémica" para "designar las formas en que se inscriben los acontecimientos en la memoria." Las huellas mnémicas se depositarían, según Freud, en diferentes sistemas en los que persisten de un modo permanente, pero sólo son reactivadas una vez catectizadas. Freud se propone situar la memoria dentro de una tópica y explicar su funcionamiento en términos económicos. La concepción de la amnesia infantil puede aclarar la teoría metapsicológica de las huellas mnémicas. Para Freud el hecho de que no recordemos los acontecimientos de la vida infantil es consecuencia de la represión. Todos los recuerdos quedarían inscriptos, su evocación dependería de la catexis, la contracatexis y el retiro de la catexis. Esta concepción se debe a la diferenciación entre la representación y el cuantum de afecto.
} 
le ayudasen a pensar el funcionamiento psíquico en relación a la memoria, Freud finalmente encuentra la Pizarra mágica o el Bloc maravilloso. Ahora bien: "Indudablemente Freud no maneja metáforas si manejar metáforas es hacer alusión con lo conocido a lo desconocido. Mediante la insistencia de su inversión metafórica, vuelve enigmático, por el contrario, aquello que se cree conocer bajo el nombre de escritura"17. La memoria sería esta escritura psíquica, inscripciones que la vida (y la muerte) deja en los cuerpos.

La economía que instaura la pulsión de muerte permite pensar la lógica mediante la cual funciona el psiquismo: la repetición, el carácter eminentemente conservador de la pulsión, pero al mismo tiempo, la división y la diferencia. Así, el gasto y la presencia que significan el encuentro con la realidad, son diferidos mediante el abrirse paso o la repetición.

¿No es esto ya la muerte en el principio de una vida que no puede defenderse contra la muerte más que por la economía de la muerte, la diferencia, la repetición, la reserva? Pues la repetición no sobreviene a la impresión primera, su posibilidad está ya ahí, en la resistencia que ofrecen las neuronas psíquicas la primera vez. La resistencia misma no es posible más que si la oposición de fuerzas perdura o se repite originariamente. Lo que se vuelve enigmático es la idea de primera vez. [...] en la primera vez del contacto entre dos fuerzas la repetición ha comenzado. ${ }^{18}$

El carácter repetitivo y positivo de la repetición es instaurado por la economía de la pulsión de muerte cuyo movimiento inaugural es imposible de fechar. La vida está ya amenazada por este abrirse-paso que constituye la memoria y al que la vida misma resiste, pero que finalmente repetirá en un intento de contener la "rotura" causada. El abrirse-paso no se realiza sin dolor, pero es gracias a este dolor que la vida se instaura. Ahora bien, es también gracias a estos abrirse-paso por los que son diferidos tanto el dolor como la muerte misma. Si así no fuera peligraría la organización psíquica. En este sentido podemos decir que la vida se instituye a partir de la muerte, de lo inanimado que estaba al comienzo, hacia lo que la pulsión de muerte tiende y que la vida difiere mediante estos mecanismos psíquicos. ${ }^{19}$ Es mediante esta economía que la vida adviene. "Indudablemente la vida se protege a sí

\footnotetext{
17 Derrida, J., La escritura y la diferencia, 1989[1967], Ed. Anthropos, Barcelona, p. 275.

18 Ibidem, p. 279.

19 Posiblemente la economía que instaura la pulsión de muerte esté relacionada con lo que Bataille llama "gasto libre": "Y es así como la inmensa quiebra de la actividad arrastra a las actividades humanas -incluidas las que se asocian con las actividades económicas- hacia el juego calificador de la materia universal: la materia, en efecto, no puede ser definida más que por la diferencia no lógica [...] Los hombres aseguran su subsistencia o evitan el sufrimiento no porque estas funciones impliquen por sí mismas un resultado suficiente, sino para acceder a la función insubordinada del gasto libre" (Bataille, «La noción de gasto», La critique sociale $N^{\circ} 7,1983$, pag.12)
} 
misma mediante la repetición, la huella, la diferencia. Pero hay que tener cuidado con esa formulación: no hay vida primero presente que a continuación llegase a protegerse, a aplazarse, a reservarse en la diferencia." 20

¿Cómo lee Freud estas inscripciones? Desde ya apartado de los códigos que pretenden "traducir" de forma lineal y general todo aquello que en el psiquismo es particular. "Indudablemente Freud piensa que el sueño se desplaza como una escritura original, que pone en escena las palabras sin someterse a ellas; indudablemente, piensa aquí en un modelo de escritura irreductible al habla y que comporta como los jeroglíficos, elementos pictográficos, ideogramáticos y fonéticos."21 "Original" en este texto no es utilizado en el sentido de primario y único, sino más bien, en el sentido de particular, en el que no es posible ninguna traducción directa sin pérdida. "La escritura psíquica, por ejemplo la del sueño que sigue «antiguos pasos abiertos», simple momento de regresión hacia la escritura primaria, no se deja leer a partir de ningún código. (...) El soñador inventa su propia gramática."22 No hay, en este sentido, un texto ya escrito que haya que descifrar, la lectura del texto es siempre una interpretación posible, nunca la verdad de una certeza (re)encontrada. La verdad no es un valor absoluto, presente, dicho de una vez y para siempre; sino que se construye a destiempo a partir de aquellos detalles que encontramos a pie de páginas o en las últimas palabras de un libro.

\section{Del texto neobarroco: Severo Sarduy}

Si elegimos la poética de Sarduy para pensar la escritura no es sólo porque consideramos que muchos de sus ensayos sobre el barroco/neobarroco avanzan en la crítica al logocentrismo; sino porque es propiamente en su letra donde es posible leer un modo de comprender a la escritura en tanto artefacto que desestabiliza las formas convencionales de la narrativa.

Severo Sarduy forma parte de ese linaje literario al que se ha nombrado neobarroco latinoamericano. Sabemos que la denominación neobarroco hace referencia al barroco del Siglo de Oro español. Referencia que no es una reproducción o una traducción a estas latitudes, sino que la misma marca, justamente, la imposibilidad de dicha traducción. El procedimiento poético de Góngora deja abierta la posibilidad de alguna 'traducción' al sentido más convencional que sería, dice Sarduy, índice de una consonancia "con la homogeneidad y el ritmo del logos exterior que lo organiza y precede, aún si ese logos se caracteriza por su infinitud, por lo inagotable de sus desdoblamientos". Por el contrario, el 'barroco' contemporáneo, el 'neobarro-

\footnotetext{
20 Derrida 1989[1967], op.cit. (nota 17), p. 280.

21 Ibidem, p. 288.

22 Ibidem, p. 289.
} 
co’ rompe toda ilusión de traductibilidad a un sentido final, reflejando, según Sarduy "la desarmonía, la ruptura de la homogeneidad del logos en cuanto absoluto"23. En efecto, Sarduy considera que:

Ese barroco furioso, impugnador y nuevo no puede surgir más que en las márgenes críticas o violentas de una gran superficie -de lenguaje, ideología o civilización-: en el espacio a la vez lateral y abierto, superpuesto, excéntrico y dialectal de América: borde y denegación, desplazamiento y ruina de la superficie renaciente española, éxodo, trasplante y fin de un lenguaje, de un saber. ${ }^{24}$

\section{Lo barroco: comencemos por su etimología:}

en ese vértigo de génesis que otorga a la filología un saber excesivo y subraya sus límites logocéntricos.[...] así, del barroco perdura la imagen nudosa de la gran perla irregular -del portugués barroco-, el áspero conglomerado rocoso -del español berrueco y luego berrocal-, y más tarde, como desmintiendo ese carácter de objeto bruto, de materia basta, sin fractura, barroco aparece entre los joyeros: invirtiendo su connotación primera, ya no designará más lo inmediato y natural, piedra y perla, sino lo elaborado y minucioso, lo cincelado, la aplicación del orfebre. ${ }^{25}$

Lo barroco señala la desviación de la forma precedente: lo clásico, equilibrado y puro. Esta desviación no ha estado exenta de una valoración moral. Como dice Sarduy, el barroco estaba destinado desde su nacimiento a la ambigüedad, a la difusión semántica.

Los textos del neobarroco latinoamericano escenifican el grueso entramado de tejidos y texturas múltiples que absorben de espacios diversos. Es posible analizar estas herencias a partir de lo que Sarduy llama la intertextualidad y la intratextualidad, fragmentos de otros textos, un remitirse perpetuo en el que el origen aparente no hace más que perderse. Escritura que no remitiendo sino más que a otras escrituras, desplaza infinitamente el nombre de la cosa. La cosa se encuentra justamente en la diferencia, en los blancos que deja la arabesca escritura. El sentido, entonces, no sólo asoma incompleto en el juego de la metáfora y la metonimia, sino también en las complejas superposiciones semánticas, sintácticas, silábicas, fónicas, etc., del exceso barroco.

Los elementos que permiten, entonces, una semiología del barroco son la intertextualidad y la intratextualidad. La primera juega con la cita, muchas veces textuales y otras implícitas que determinan el tono en que un texto es legible. La intratextualidad agrupa los textos "en filigrana que no son introducidos en la aparente

\footnotetext{
23 Perlongher, N., Papeles Insumisos, Buenos Aires, Santiago Arco Editor, 2004, p. 229.

24 Sarduy 1999, op.cit. (nota 1), p. 1308.

25 Ibidem, p. 1199.
} 
superficie plana de la obra como elementos alógenos - citas y reminiscencias-, sino que, intrínsecos a la producción escriptural, a la operación de cifraje -de tatuaje- en que consiste toda escritura, participan, conscientemente o no, del acto mismo de la creación. Gramas que se deslizan, o que el autor desliza, entre los trazos visibles de la línea, escritura entre la escritura." 26 ¿Qué son esas huellas, gramas entre la escritura? ¿Qué es esa otra escritura? Tal vez esa différance que permite que en el juego del cifraje que es producido y que produce la escritura, algo sea dicho.

"¿Qué significa hoy en día una práctica del barroco? [...] ser barroco hoy significa amenazar, juzgar y parodiar la economía burguesa, basada en la administración tacaña de los bienes, en su centro y fundamento mismo: el espacio de los signos, el lenguaje, soporte simbólico de la sociedad, garantía de su funcionamiento, de su comunicación. Malgastar, dilapidar, derrochar lenguaje únicamente en función del placer." $27 \mathrm{El}$ barroco se complace en el suplemento, en el gasto sin reservas, sin sentido económico. ¿Se trata quizás de otra economía, de una aneconomía? Mientras que la obra clásica es entendida como trabajo, el neobarroco es comprendido como juego: repetición obstinada de lo inútil.

Unas palabras más en torno al neobarroco, intento de justificación, siempre après coup, de una elección. El neobarroco es una de las formas por las que el paradigma logofonocéntrico se ve desbordado por una escritura que no intenta comunicar, que se desliza sobre líneas discontinuas de musicalidad diversa, un lenguaje que mezcla sin cesar tonos, figuras, lenguas (idiomas, pero también espacios escriturales -pintura, arquitectura, teatro-, etc.). Mientras en el barroco europeo el logos sigue siendo la autoridad que equilibra los dos ejes epistémicos del siglo: dios y el rey; el neobarroco "refleja estructuralmente la inarmonía, la ruptura de la homogeneidad, del logos en tanto que absoluto, la carencia que constituye nuestro fundamento epistémico. Neobarroco del desequilibrio, reflejo estructural de un deseo que no puede alcanzar su objeto, deseo para el cual el logos no ha organizado más que una pantalla que esconde la carencia." 28

El neobarroco es esa escritura que impugna la lógica logocéntrica de la escritura lineal, desestabiliza cualquier intento de instalarse en un determinado lugar; lo hace para "metaforizar al orden discutido, al dios juzgado, a la ley transgredida. Barroco de la Revolución." 29

La escritura barroca, como todas las demás, no remite más que a sí misma. No hay una realidad a describir, que narrar, es sobre la letra escrita que se escribe para no decir más que el juego de sus diferencias. Ningún mundo ideal/real que historiar, que recordar, sino memoria y olvidos a construir, a espejar. La escritura es para

\footnotetext{
26 Ibidem, p. 1398.

27 Ibidem, p. 1250.

28 Ibidem, p. 1252.

29 Ibidem, p. 1253.
} 
Sarduy "Esa tachadura del rostro original, mácula en la definición casi huraña del modelo que viene a introducirse como un suplemento ruidoso y a perturbar la reflexión -en los dos sentidos del término: concentración mental y reproducción especular." 30 La escritura es entonces, un sismo que disloca la tranquilidad del saber que genera el logos reproductor.

Sarduy subraya: "Si la escritura constituye al sujeto, lo define a sí mismo y lo sutura, su Ersatz reflejado, o más bien parásito de su reflejo, lo resquebraja, fragmenta su representación y la desune. La duplicación del rostro atravesada por la grafía se va separando, abriendo: deriva de islotes faciales, placas tectónicas que empuja y separa un magma incandescente de letras: flujo atomizado y naranja de fonemas cortantes, sangre cifrada." 31 En la escritura del cuerpo algo siempre escapa, tal vez algo que persiste como el magma, el fondo en el cual lo escrito permanece.

\section{La experiencia de la escritura: Sarduy y Derrida}

En Feu la cendre (1987) Derrida alude a la ceniza, pero también al fuego y al difunto. No sólo reflexiona acerca de lo que podría ser una metáfora de la misma, sino que trabaja explícitamente (casi literalmente) a partir de cenizas dispersas de otros textos. En un nuevo intento de pensar lo que está más allá del logos, de la voz, de la vida presente para sí misma, en esta ocasión, Derrida recurre a la ceniza. A continuación intentaremos articular, a partir de este motivo, la escritura y el tiempo en los textos de Sarduy y Derrida. Con ello pretendemos continuar pensando lo que se halla más allá de los restos memorables, eso que perturba todo acto de memoria y que insiste como aquello imposible olvidar.

Como sabemos, la palabra $f e u$ hace referencia en francés tanto al fuego como al difunto ${ }^{32}$. El fuego a su paso devora, consume lo que encuentra, haciendo desaparecer la estructura formal de aquello que fue y que ya nunca más será. Pero el fuego no es algo que estaría afuera de lo que consume y que advendría separadamente del mismo, sino que es(tá) contenido, está al interior mismo de lo que devora, poder destructor, pero también energía productora de la vida. El fuego (es) como un holocausto que lo quema todo, tal vez, para advenir de otro modo.

La diferencia y el juego de la luz pura, la diseminación pánica y pirómana, el quematodo se ofrece en holocausto al para sí, gibt sich dem Fürsichsein zum Opfer. Se sacrifica, pero lo hace para restar, para asegurar su conservación, para vincularse consigo

\footnotetext{
30 Ibidem, p. 1317.

31 Ibidem, p. 1318.

32 En la acepción de difunto, la palabra feu es una abreviación del latín défunt, de functus, functus vitâ: “dèbarrassé de la vie, qui s'est acquitté de la vie." (Dictionnaire Nacional Bescherelle, 1870, p. 1248).
} 
mismo, estrictamente, para convertirse él mismo en para sí, junto a sí. Para sacrificarse se quema. [...] ¿Qué se pone en juego en este holocausto del juego mismo? Quizás ésto: el don, el sacrificio, la puesta en juego o en fuego de todo [...] El don no es, el holocausto no es, al menos si los hay. Pero en cuanto (que) quema (el incendio no es un ente) debe, quemándose a sí mismo, quemar su operación de quemar y comenzar a ser. ${ }^{33}$

¿Qué se pone en juego en este holocausto del juego mismo? Quizás una lógica diferente: la del don, la del sacrificio, de aquello que no podría entrar nunca en la lógica especulativa del intercambio. Una lógica que subvierte las relaciones establecidas.

Lo que resta del paso del fuego es la ceniza. El fuego aparece en los intersticios de lo que quema, pero lo quemado sólo es a partir de una quema. Y cuando el incendio se extingue no queda nada del fuego. Consume lo que abraza sin dejar marca. $\mathrm{Y}$ al final y al principio del fuego, cenizas. Pero ¿hay algo que diferencie, que difiera entre las cenizas? Tal vez, sólo el tiempo de la quema en que se nos va la vida.
Menos fervor que anatema,
más pena que regocijo,
así permanece, fijo
como el oro de un emblema
indiferente a la quema,
El tiempo de los amantes:
no ahora, no después, ni antes.
Muda extensión de lo inerte
que sólo el gozo y la muerte
apresan. Unos instantes.

¿El tiempo es lo único que permanece indiferente a la quema, al fuego? El tiempo se halla más allá de cualquier lógica del intercambio: es pura pérdida, gasto inútil, donación que genera una deuda imposible de saldar. El tiempo (está) si bien presente entre nosotros, es aquello imposible de aprehender. Y sin embargo, estructura la vida y la muerte. Testigo perenne de la historia, silencioso compañero de los días. Tal vez, el cuerpo es la prueba fiel de su presencia en la forma de la ausencia dolorosa.

Como la escritura, el cuerpo del sujeto siempre deviene a partir de otros cuerpos. No hay una escritura original: siempre se escribe sobre la letra de otros textos. La lógica que hemos intentado plantear en este trabajo atraviesa los objetos partiéndolos y dispersándolos, ya no es posible encontrarlos haciéndose uno consigo mismo: es una lógica que perturba la posibilidad de la unidad y de la identidad. Y en este sentido, lo que diferencia a la ceniza del objeto no es el fuego, sino el tiempo transcurrido de uno al otro. Así lo que los separa para siempre y desde siempre es la huella. "El ser sin presencia no ha sido ni tampoco será ahí donde hay la ceni-

33 Derrida, J., La difunta ceniza- Feu la cendre, Ed. Bilingüe, Buenos Aires, La Cebra, 2009, pp. 32-34. 
za y donde hablaría esa otra memoria." 34 ¿Qué es esa otra memoria? Quizás una memoria que escapa al poder reductor del saber recordar. Una memoria que con el mismo gesto nos arrebata el recuerdo, pero por ello mismo, nos insta a seguir en la búsqueda de la huella.

$\mathrm{Si}$ "no hay ceniza más que con respecto al hogar, al foco, algún fuego, algún difunto, o lugar..." 35 , es que no es posible nada sin una deuda con algún muerto. Seguidamente, Derrida propone la ceniza como casa del ser, metáfora con la que indudablemente está haciendo referencia a Heidegger para quien el lenguaje es la morada del ser. ¿Qué intenta Derrida al proponer la ceniza como la morada del ser? Quizás el motivo de la ceniza permita pensar la dispersión, la diferencia, pero al mismo tiempo lo intangible, la imposibilidad de aprehenderla o, en todo caso, de conocer el origen, el nombre del difunto, la dirección del hogar. La ceniza escapa a la determinación geográfica por su poder de dispersión, pero es cierto que tuvo que haber algo que se quemase en algún sitio. Las cenizas permiten pensar ese resto, esa marca que se borra y dispersa sin ninguna posibilidad de volver a ser una consigo misma. Pero además, dibuja esa cartografía corporal en la que el cuerpo está compuesto de pequeñas partículas que así como se juntan se separan, se fragmentan, fragmentando desde siempre el cuerpo del que formaron parte. De alguna forma su discurrir es nómada: "-pero eso es justamente lo que él llama la huella, ese borrarse. Tengo ahora la impresión de que el mejor paradigma de la huella, para él, no es, como algunos lo creyeron y él también quizás, la pista de caza, el abrirse-paso, el surco en la arena, la estela en el mar, el amor del paso por su impronta, sino la ceniza (lo que resta sin restar del holocausto, del quema-todo, del incendio el incienso)." 36

En el pensamiento de la memoria se trata entonces, del cuerpo cifrado marcado con las huellas del tiempo por el que es posible que algo se herede, algo se transfiera, algo pase de generación en generación. Tal vez, esa memoria trans-generacional a la que aludía Freud.

Ni firmas, ni firmamento, ni el mar con su gris sereno, no ruinas, sueño, veneno, gozo, quejido, contento. Todo se lo lleva el viento con su rauda polvareda. Huesos sí. Más no remeda la minuciosa armadura más que el rostro y la figura: uñas y pelo, eso queda. 
Sin duda, la ceniza es lo que queda del difunto, pero además, dice Sarduy, nos quedan las uñas y el pelo, justamente las únicas partes del cuerpo que continúan creciendo más allá de la vida de quien las porta. Así, la herencia sigue fructificando más allá de la firma y el nombre propio.

\author{
Que no se nombre ni evoque \\ este mal, o este castigo, \\ que disfrazado de amigo \\ se infiltra aún más. Que no toque \\ mi piel su ponzoña, o lo que emigra \\ de hueso a hueso, \\ de sangre a sangre, de seso \\ a semen: un mismo blanco \\ ofrece al morbo su flanco \\ endeble: la vida es eso.
}

Para quien por el momento sobrevive a la quema, el proceso de duelo determinará y marcará su cuerpo. ¿Qué es lo que emigra de hueso a hueso, de sangre a sangre, de seso a semen? Quizás, la mortalidad de la que estamos constituidos; la muerte: doble de la que la vida es sólo su otra cara.

¿Qué hay al final y al principio? Cenizas. Cenizas de lo que fue y ya no será, pero gracias a lo que otra cosa advendrá. Así, el duelo ${ }^{37}$ que inaugura la ceniza, inaugura el espacio del posible acontecimiento. En la herencia se juega siempre una deuda. La escritura reconoce esa deuda. "Separándose de sí misma, formándose allí toda ella, casi sin resto, de un solo trazo la escritura reniega y reconoce la deuda. Hundimiento extremo de la firma, lejos del centro, incluso de los secretos que allí se comparten para dispersar hasta su ceniza." 38

Duro trabajo es el duelo, que no se aprende ni olvida ni a lo largo de la vida

\footnotetext{
37 El duelo es, sin lugar a dudas, el tema que atraviesa toda la temática de la memoria y el olvido que, por razones de extensión, no abordamos en este trabajo. La problemática del duelo en el contexto de las circunstancias socio-históricas que caracterizaron este milenio, interroga críticamente las construcciones teóricas acerca de lo que un trabajo de duelo parece implicar. Precisamente es este proceso el que nos interesa indagar en tanto relación particular con el otro: "Memoria e interiorización desde Freud, así es como a menudo se describe el «trabajo de duelo» «normal».(...) [que] mantiene dentro de nosotros la vida, el pensamiento, el cuerpo, la voz y la mirada o el alma del otro, pero en la forma de esos hypomnemata, memorandos, signos o símbolos, imágenes o representaciones mnésicas que son sólo fragmentos discontinuos, distantes y dispersos, sólo "partes» del otro ausente." (Derrida, 1989, p. 45-47)

38 Derrida, 2009, op. cit (nota 33), p. 16.
} 
se perfecciona. Desvelo

inútil: porque a más celo

menos ganancia. A la obra

algo le falta o le sobra

para alcanzar su estatura

-que es el olvido-. Sutura

con lo que no se recobra.

"Entiendo que la ceniza no es nada que esté en el mundo, nada que reste como ente. Es el ser, más bien, que hay -es un nombre del ser que hay ahí pero que, al darse (es gibt ashes), no es nada, resto más allá de todo lo que es (konis epekeina tes ousias), resto impronunciable para hacer posible el decir a pesar de que no es nada." 39 Esta nada que es la ceniza, ya que ha borrado en el proceso de la quema la estructura formal de lo que fue (el ente, del que no queda nada), deviene la posibilidad de pensar el ser en un sentido de alguna manera "material" (más allá de cualquier metafísica).

Como distintos relatos
sin ilación y cotejo,
aparece en el espejo
un laberinto de estratos
superpuestos: garabatos
nocturnos, emblemas mudos,
cuerdas, arabescos, nudos,
anclas, madejas que apresan:
enigmas que se enderezan
en nuestros cuerpos desnudos. 40

Plantear la memoria y el olvido como cenizas perturba la línea de separación tajante entre la vida y la muerte, para transmigrar entre ellas. Implica reconocer que esos huesos, ahora cenizas, están en nosotros. Así, si el sujeto adviene, como dijo Freud, a partir de su memoria: somos un complejo entramado de huellas que, imborrables, nos determinan en este laberinto de estratos complejos (social, político, subjetivo, instintivo, ético, étnico, etc.).

¿Qué hay en el comienzo, en el origen sin origen? Tal vez, sólo cenizas que el viento, sin duda, dispersará.

39 Ibidem, p. 59.

40 Sarduy, 1999, op.cit. (nota 1), pp. 213-216. 